\title{
Children and adolescents with type 1 diabetes eat a more atherosclerosis-prone diet than healthy control subjects
}

\author{
N. C. Øverby • V. Flaaten • M. B. Veierød • I. Bergstad • \\ H. D. Margeirsdottir $\cdot$ K. Dahl-Jørgensen • \\ L. F. Andersen
}

Received: 14 June 2006 / Accepted: 10 October 2006 / Published online: 29 November 2006

(C) Springer-Verlag 2006

\begin{abstract}
Aims/hypothesis We evaluated how well the diet of Norwegian children and adolescents with type 1 diabetes fulfils the Nordic and European dietary recommendations, focusing on parameters affecting prevention of atherosclerosis. We also compared the diet of this patient group with that of healthy same-age control subjects.

Materials and methods A total of 177 children and adolescents with type 1 diabetes (9-10-year-olds, 12-13year-olds) and 1,809 healthy same-age control subjects
\end{abstract}

N. C. Øverby $(\bowtie) \cdot$ V. Flaaten $\cdot$ M. B. Veierød $\cdot$ L. F. Andersen Department of Nutrition, Institute of Basic Medical Sciences, Faculty of Medicine, University of Oslo,

$\mathrm{Pb} 1046$ Blindern,

0316 Oslo, Norway

e-mail: ninaco@medisin.uio.no

M. B. Veierød

Department of Biostatistics, Institute of Basic Medical Sciences, Faculty of Medicine, University of Oslo,

Oslo, Norway

I. Bergstad

Department of Nutrition and Dietetics, Aker University Hospital, University of Oslo,

Oslo, Norway

H. D. Margeirsdottir · K. Dahl-Jørgensen

Department of Pediatrics,

Ullevaal University Hospital, University of Oslo,

Oslo, Norway

H. D. Margeirsdottir · K. Dahl-Jørgensen

Diabetes Research Center,

Aker and Ullevaal University Hospitals, University of Oslo,

Oslo, Norway recorded their food intake for 4 days in precoded food diaries.

Results In children and adolescents with type 1 diabetes the percentage of energy (E\%) from fat (33-35 E\%) and saturated fat (14-15 E\%) was higher than recommended for that group. Furthermore their intake of fibre was lower (16-19 g/day) than current recommendations. There were no differences in energy intake between diabetic subjects and healthy control subjects. Percentage of energy from fat (mean difference: $3.4 \mathrm{E} \%, p<0.001$ ) and saturated fat (mean difference: $1.0 \mathrm{E} \%, p<0.001$ ) was significantly higher among diabetic subjects than control subjects. Intake of fruits and vegetables was low ( $210 \mathrm{~g} /$ day) compared with recommendations, both in the diabetic and control subjects. Conclusions/interpretation Diabetic children and adolescents had a high intake of energy from saturated fat and low intake of fibre, fruits and vegetables, which could increase the risk of development of atherosclerosis. This study supports the idea that nutritional guidance in the treatment of children and adolescents with type 1 diabetes should be more focused, especially with regard to intake of fibre, fruits and vegetables and to quality and quantity of fat intake.

Keywords Adolescents · Atherosclerosis · Children · Diet . Type 1 Diabetes
Abbreviations
DNSG Diabetes and Nutrition Study Group
E\% Percentage of Energy
MUFA Monounsaturated Fatty Acids
NCDQ Norwegian Childhood and Diabetes Quality Project
NNR Nordic Nutrition Recommendations 


\section{Introduction}

It is well established that type 1 diabetic children and adolescents have an increased risk of cardiovascular disease compared to the general population $[1,2]$. The multi-centre study EURODIAB found that low intake of saturated fat and high intake of fibre reduced the risk of cardiovascular disease among type 1 diabetic subjects [3, 4]. The development of atherosclerosis starts during childhood and adolescence [5-8]; moreover imaging techniques have shown that atherosclerosis develops earlier in diabetic children than in age-matched control subjects $[1,9]$. Thus compliance with nutrition recommendations is especially important for children and adolescents with type 1 diabetes. Nevertheless, only a few studies have examined the dietary intake of children and adolescents with type 1 diabetes [10 17], most of them performed more than 10 years ago and exploring relatively small sample sizes [11-17]. In a large American cohort it was found that young people with diabetes substantially failed to meet current recommendations and that there was a critical need for improvement in dietary intake among diabetic adolescents [10].

In Norway, dietary recommendations for children and adolescents with type 1 diabetes are similar to the recommendations for the healthy population, namely the Nordic Nutrition recommendations (NNR) [18]. These recommendations are comparable to the new European recommendations: 'Evidence-based nutritional approaches to the treatment and prevention of diabetes mellitus' published by the Diabetes and Nutrition Study Group (DNSG) of the European Association for the Study of Diabetes [19]. The present study aimed to evaluate how well the diet of children and adolescents with type 1 diabetes fulfils the NNR and the new European dietary recommendations, and to compare the diet of this group with healthy same-age control subjects.

\section{Subjects and methods}

Subject recruitment and characteristics The children and adolescents with type 1 diabetes were recruited from participants in the Norwegian Childhood Diabetes and Quality project (NCDQ) [20]. This is a prospective population-based study for research and quality improvement by means of benchmarking, and includes all children and adolescents (age range: 3-19 years) with type 1 diabetes from 24 of 25 Norwegian paediatric departments. The diagnosis was ensured by measurement of autoantibodies (insulin, GAD, insulinoma antigen) and C-peptide. Children with type 2 diabetes were not included. Among the participants, 446 children were born in 1990 and 1991 (aged 12-13 years) and 1994 to 1995 (aged
9-10 years); these children were invited to participate in the dietary study. A total of 209 wanted to participate, and 177 completed the study (participation rate: $41 \%$ ).

The diabetic subjects were compared with healthy control subjects from the UNGKOST-2000-study [21]. A total of 810 students in 4th grade ( 9 years old) and 1,005 students in 8th grade (13 years old), drawn from a random national representative sample of 103 schools from 53 municipalities, participated. Six of these children had diabetes and were excluded. The final sample included in the present study was 808 9-year-olds (participation rate: $81 \%$ ) and 1,001 13-year-olds (participation rate: $84 \%$ ) (for further details see [21]).

Selected characteristics of the study samples are given in Table 1. By multiple regression analysis adjusted for sex and age, we found that diabetic subjects weighed more (adjusted mean difference: $1.81 \mathrm{~kg}$ for diabetic subjects vs control subjects, 95\% CI $0.47-3.15, p=0.008)$ and their BMI was higher (adjusted mean difference: $0.75 \mathrm{~kg} / \mathrm{m}^{2}$ for diabetic subjects vs control subjects, 95\% CI $0.32-1.19$, $p=0.001$ ) than the control subjects, but there were no significant differences in height (adjusted mean difference: $-0.15 \mathrm{~m}$ for diabetic subjects vs control subjects, $95 \% \mathrm{CI}$ -1.36 to $1.06, p=0.81)$. The diabetic subjects had reasonable metabolic control. $\mathrm{HbA}_{1 \mathrm{c}}$ was lower among 9-10-yearolds than among 12-13-year-olds. Serum lipids were within target levels to prevent cardiovascular disease [1], except for LDL-cholesterol among girls in the 9-10-year-old age group, which was above the recommended level (Table 1). No significant differences were found in the duration of education between the parents of diabetic subjects and those of control subjects (fathers' education: $p=0.50$, mothers' education: $p=0.18$ ). Among the parents of diabetic subjects, $56 \%$ of the mothers and $63 \%$ of the fathers had an education of less than 12 years of schooling, while the percentages among parents of control subjects were $61 \%$ and $60 \%$, respectively.

The study protocols were approved by the National Committee for Research Ethics in Norway and the Norwegian Social Science Data Services. Informed consent was obtained from the parents and additionally from adolescents older than 12 years of age.

Study design Data collection among the diabetic subjects was carried out from January to April 2004. They received an invitation letter and a questionnaire by mail. Those who agreed to participate returned an informed consent form and the completed questionnaire to the University of Oslo. Diaries, instruction video and an information letter were sent to the participants. One written reminder was sent to those who did not respond the first time.

Data collection among the control subjects was carried out from September until the first week of December 2000. 
Table 1 Characteristics of diabetic and control subjects

\begin{tabular}{|c|c|c|c|c|c|c|c|c|}
\hline & \multicolumn{4}{|c|}{$9-10$-year-olds } & \multicolumn{4}{|c|}{ 12-13-year-olds } \\
\hline & \multicolumn{2}{|l|}{ Boys } & \multicolumn{2}{|l|}{ Girls } & \multicolumn{2}{|l|}{ Boys } & \multicolumn{2}{|l|}{ Girls } \\
\hline & $\begin{array}{l}\text { Diabetic } \\
\text { subjects } \\
(n=40)\end{array}$ & $\begin{array}{l}\text { Control } \\
\text { subjects } \\
(n=402)\end{array}$ & $\begin{array}{l}\text { Diabetic } \\
\text { subjects } \\
(n=31)\end{array}$ & $\begin{array}{l}\text { Control } \\
\text { subjects } \\
(n=406)\end{array}$ & $\begin{array}{l}\text { Diabetic } \\
\text { subjects } \\
(n=62)\end{array}$ & $\begin{array}{l}\text { Control } \\
\text { subjects } \\
(n=489)\end{array}$ & $\begin{array}{l}\text { Diabetic } \\
\text { subjects } \\
(n=44)\end{array}$ & $\begin{array}{l}\text { Control } \\
\text { subjects } \\
(n=512)\end{array}$ \\
\hline Age (years) & $8.5(0.6)$ & $8.9(0.3)$ & $8.8(0.6)$ & $8.9(0.3)$ & $12.7(0.7)$ & $12.9(0.3)$ & $12.7(0.7)$ & $12.9(0.3)$ \\
\hline Height $(\mathrm{cm})$ & $137.7(6.7)$ & $137.2(6.4)$ & $137.1(7.2)$ & $136.7(7.0)$ & $159.8(10.4)$ & $160.5(9.3)$ & $160.7(7.3)$ & $161.0(6.6)$ \\
\hline Weight (kg) & $33.7(5.6)$ & $32.4(6.0)$ & $32.1(5.1)$ & $31.9(6.3)$ & $52.2(12.0)$ & $49.3(10.4)$ & $51.3(8.7)$ & $49.5(8.5)$ \\
\hline BMI $\left(\mathrm{kg} / \mathrm{m}^{2}\right)$ & $17.7(2.1)$ & $17.1(2.5)$ & $17.0(1.9)$ & $17.1(2.7)$ & $20.2(2.9)$ & $19.0(2.8)$ & $19.9(2.6)$ & $19.1(2.8)$ \\
\hline Diabetes duration (years) & $2.8(2.1)$ & - & $2.8(2.0)$ & - & $4.9(3.2)$ & - & $4.7(3.2)$ & - \\
\hline $\mathrm{HbA}_{1 \mathrm{c}}(\%)$ & $7.5(0.8)$ & - & $7.3(0.8)$ & - & $7.8(0.8)$ & - & $8.0(1.1)$ & - \\
\hline $\begin{array}{l}\text { Hypoglycaemic incidents } \\
\text { (number per year) }^{\mathrm{a}}\end{array}$ & $2.7(7.7)$ & - & $1.0(3.5)$ & - & $2.8(8.5)$ & - & $3.1(11.9)$ & - \\
\hline HDL-cholesterol $(\mathrm{mmol} / \mathrm{l})^{\mathrm{b}}$ & $1.9(0.5)$ & - & $1.7(0.4)$ & - & $1.7(0.4)$ & - & $1.8(0.5)$ & - \\
\hline LDL-cholesterol $(\mathrm{mmol} / \mathrm{l})^{\mathrm{b}}$ & $2.3(0.5)$ & - & $2.7(0.6)$ & - & $2.2(0.6)$ & - & $2.4(0.6)$ & - \\
\hline Under-reporters $(n[\%])$ & $0(0)$ & $18(4.5)$ & $2(6.5)$ & $18(4.4)$ & $10(16.1)$ & $86(17.6)$ & $7(15.9)$ & $96(18.8)$ \\
\hline
\end{tabular}

Values are mean (SD).

${ }^{a}$ Number of hypoglycaemic incidents with need of help from others

${ }^{\mathrm{b}}$ HDL- and LDL-cholesterol are non-fasting

The control subjects received an invitation letter and a questionnaire at school. A nutritionist visited each class and gave oral and written instructions on how the diet should be recorded [21].

All participants, both diabetic and control subjects, recorded their entire food intake for four consecutive days ( 3 week days, 1 weekend day) in an 18-page pre-coded food diary. On the second day a nutritionist called everyone to hear if they had any questions and to encourage them to finish the registration.

Participants aged 12-13 years mainly recorded their diet themselves; while the parents filled in the data for children aged $9-10$ years.

Questionnaire The questionnaire included questions about height and weight, and parents' education (further details: [22]). Data on height and weight were self-reported, with $85 \%$ of participants replying to the relevant questions. Information on duration of diabetes, numbers of hypoglycaemic incidents and serum lipids were obtained from case record forms of the NCDQ for $83 \%$ of the participants.

Food diary The diary has lists of 277 drinks, food items and dishes, grouped together according to a typical Norwegian diet. Each food group is supplemented with open-ended alternatives. Food amounts are presented in predefined household units or as portions estimated from photographs in a photographic booklet [21]. The food diary has been validated and the energy intake was found to be underestimated by $18 \%$ compared with energy expenditure measured by Acti Reg [23]. The photographic booklet contains 13 colour photograph series, each with four different portion photographs. A validation study showed that the photographic booklet is a useful tool for portion size estimates in these age groups [24]. The 12-min-long video instructions show a boy eating four meals and how he fills in his diary.

Calculations of dietary intake Data entry was made by scanning, using Teleform 6.0 (Datascan, Oslo, Norway). Daily intake of foods, energy and nutrients was computed using a food database and software system developed at the Department of Nutrition, University of Oslo, Norway. The food database is mainly based on the official food composition table [25], and is continuously supplemented with data on new food items and nutrients. Corrections for losses in cooking are made when calculating nutrient contents. The use of cod liver oil and vitamin and mineral supplements is included in the nutrient calculation.

Laboratory methods $\mathrm{HbA}_{1 \mathrm{c}}$ was determined by highperformance liquid chromatography (Variant; Bio-Rad, Richmond, CA, USA). All samples were sent to the same central Diabetes Control and Complications Trial-approved laboratory (Central laboratory, Aker University Hospital, Oslo, Norway). Normal reference was 4.1-6.4\% (2 SD), intra-assay $\mathrm{CV}$ was $<3 \%$. Lipid profiles were measured by conventional methods in the non-fasting state.

Definitions Self-reported weight and height were used to calculate BMI $\left(\mathrm{kg} / \mathrm{m}^{2}\right)$. Self-reported height and weight from the questionnaire have been validated, and a high 
correlation between self-reported and measured height and weight among 9-year-olds and 13-year-olds was found [22]. Added sugars refer to refined or industrially produced sugar (not including naturally occurring mono- and disaccharides) used as an ingredient in processed or prepared food.

Statistical analysis Age, height, weight, BMI and nutrient intakes are presented as means with standard deviations. Chi-square test was used to compare different groups with regard to parents' education. Crude and adjusted mean differences in height, weight, BMI and nutrient intakes between diabetic and control subjects were estimated by simple and multiple linear regression analyses, respectively. The crude model corresponds to a two sample $t$ test. The multiple models included sex and age in the analysis of height, weight and BMI, and sex, age and BMI in the analyses of nutrients. When necessary, nutrient values were $\log _{\mathrm{e}}$ transformed. Back transformation of the estimated mean difference in log-transformed intakes between diabetic and control subjects (i.e. the regression coefficient for group [diabetic vs control subjects]) yields the ratio of geometric means. Confidence intervals for the geometric mean ratio were computed by back transformation of the $95 \%$ confidence limits for the regression coefficient. Relevant interactions were tested. When interactions with group (diabetic vs control subjects) were observed, 95\% confidence intervals were estimated by means of the estimated covariance matrix for the regression coefficients, while tests of groups effects were performed separately within each strata of the relevant variable. Intakes of foods and drinks are presented as medians with $95 \%$ confidence intervals, and the Mann-Whitney $U$ test was used to compare intakes between groups. These data were skewed and $\log$ transformation did not improve this, therefore these data were analysed with non-parametric tests and no adjustment for sex was performed. To compare nutrient intake between diabetic subjects with parents with long and short education, independent-sample $t$ test was used.

All $p$ values are two-sided, and a 5\% level of significance was used. All statistical analyses were performed with SPSS 11.0 (SPSS, Chicago, IL, USA).

\section{Results}

Intakes of energy and nutrients among diabetic subjects and control subjects are presented in Table 2. Supplements, which are included in nutrient intake estimation in Table 2, were used by $41 \%$ of the participants. Diabetic subjects had a higher percentage of energy (E\%) from fat (33-35 E\%) than recommended in the NNR [18], but this percentage was still within the European dietary recommendations
[19]. Intake of saturated fat (14-15 E\%) was higher than recommended in the Nordic and the European recommendations. The maximum recommended intake of added sugars is $10 \mathrm{E} \%$ and the mean intake among diabetic subjects was 8-9 E\%. Among diabetic subjects mean intakes of all micronutrients apart from vitamin D and fibre were satisfactory compared with current recommendations. Intake of fruits and vegetables was low (210 g/day) compared with recommendations (500 g/day), both among diabetic and control subjects.

Estimated mean differences between diabetic and control subjects are presented in Table 3. Control subjects are used as the reference group, thus negative values indicate lower intakes among diabetic subjects than among control subjects. There were no significant differences between diabetic and control subjects regarding intake of energy. The diabetic subjects had a significantly higher percentage of energy from protein, fat, saturated fat, monounsaturated fatty acids (MUFA) and polyunsaturated fat than control subjects. For percentage of energy from fat there was a significant interaction with age $(p=0.02)$ and the mean difference in percentage of energy from fat was much larger among 12-13-year-olds than among 9-10-year-olds (4.7 E\% and $1.7 \mathrm{E} \%$, respectively). For intake of polyunsaturated fat, a significant interaction with $\operatorname{sex}(p=0.02)$ was observed, and there was a larger mean difference between female diabetic and control subjects (1.3 E\%) than between their male counterparts $(0.6 \mathrm{E} \%)$. Intakes of carbohydrates and added sugars were significantly lower among diabetic than among control subjects, with the mean difference in carbohydrates larger among 12-13-year-olds than among 9-10-year-olds ( $p=0.01$, test for interaction). Diabetic subjects had higher intakes of fibre, retinol equivalents, vitamin $\mathrm{D}$, thiamin, riboflavin and iron, but lower intake of vitamin $\mathrm{C}$ than control subjects.

Total intake of fruits and vegetables did not differ between the diabetic and control subjects (Table 4). Diabetic subjects in both age groups had a significantly lower intake of white bread, soft drinks with sugar and sweets, and a higher total intake of fish, meat and diet soft drinks than control subjects, while diabetic subjects aged 910 years drank significantly less fruit juices and full-fat milk than control subjects (Table 4).

Diabetic 12-13-year-olds with highly educated mothers (education $>12$ years) had a significantly higher intake of fibre ( $21 \mathrm{vs} 16 \mathrm{~g} /$ day, $p=0.005$ ) and a significantly lower intake of saturated fat (14.3 vs $15.5 \mathrm{E} \%, p=0.048)$ than those whose mothers had a shorter education ( $\leq 12$ years). Diabetic 12-13-year-olds with highly educated fathers (education $>12$ years) had a higher intake of energy (9.3 vs $8.3 \mathrm{MJ}, p=0.02$ ), fibre ( $21 \mathrm{vs} 16 \mathrm{~g} / \mathrm{day}, p=0.02$ ), and fruits and vegetables (306 vs $183 \mathrm{~g} / \mathrm{day}, p=0.01$ ) than those whose fathers' education was shorter ( $\leq 12$ years). No such 


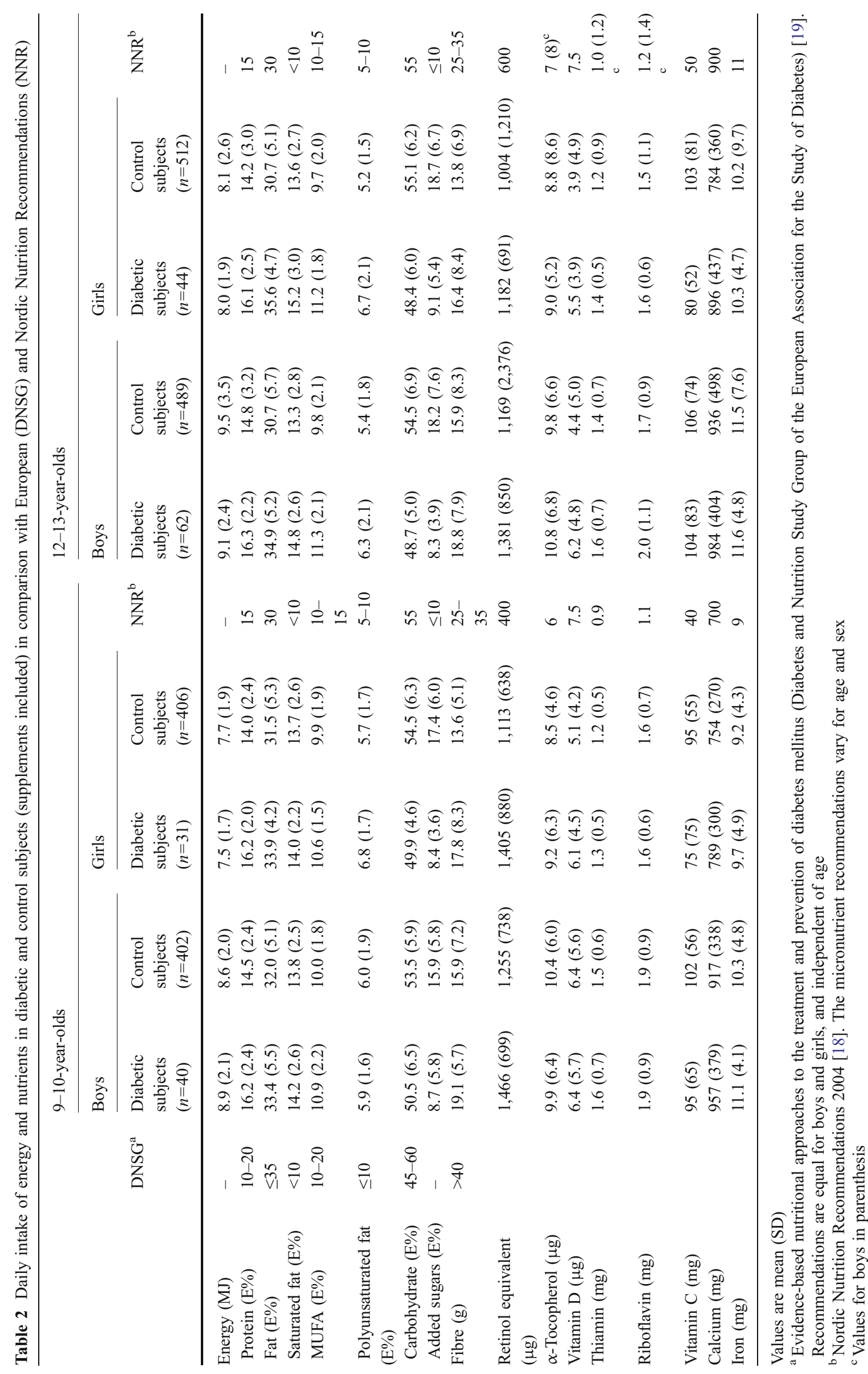


Table 3 Mean differences between diabetic subjects and control subjects in intake of energy and nutrients

\begin{tabular}{|c|c|c|c|c|c|c|c|}
\hline & \multicolumn{3}{|l|}{ Crude } & \multicolumn{4}{|l|}{ Adjusted $^{\mathrm{a}}$} \\
\hline & $\begin{array}{l}\text { Mean } \\
\text { difference }\end{array}$ & $95 \% \mathrm{CI}^{\mathrm{b}}$ & $p$-value & $\begin{array}{l}\text { Study group } \\
\text { breakdown }\end{array}$ & $\begin{array}{l}\text { Mean } \\
\text { difference }\end{array}$ & $95 \% \mathrm{CI}^{\mathrm{b}}$ & $p$-value \\
\hline Energy (MJ) & 0.01 & $(-0.4,0.4)$ & 0.96 & & -0.1 & $(-0.5,0.4)$ & 0.72 \\
\hline Protein $(\mathrm{E} \%)$ & 1.8 & $(1.4,2.3)$ & $<0.001$ & & 1.8 & $(1.4,2.3)$ & $<0.001$ \\
\hline Fat $(\mathrm{E} \%)^{\mathrm{c}}$ & 3.4 & $(2.5,4.2)$ & $<0.001$ & $\begin{array}{l}9-10 \text { years } \\
12-13 \text { years }\end{array}$ & $\begin{array}{l}1.7 \\
4.7\end{array}$ & $\begin{array}{l}(0.3,3.1) \\
(3.6,5.8)\end{array}$ & $\begin{array}{l}0.005 \\
<0.001\end{array}$ \\
\hline Saturated fat $(\mathrm{E} \%)$ & 1.0 & $(0.6,1.5)$ & $<0.001$ & & 1.1 & $(0.6,1.5)$ & $<0.001$ \\
\hline Monounsaturated fat (E\%) & 1.2 & $(0.9,1.5)$ & $<0.001$ & & 1.3 & $(0.9,1.6)$ & $<0.001$ \\
\hline Polyunsaturated fat $(\mathrm{E} \%)^{\mathrm{d}, \mathrm{e}}$ & 0.9 & $(0.6,1.1)$ & $<0.001$ & $\begin{array}{l}\text { Male } \\
\text { Female }\end{array}$ & $\begin{array}{l}0.6 \\
1.3\end{array}$ & $\begin{array}{l}(0.2,1.0) \\
(0.9,1.7)\end{array}$ & $\begin{array}{l}0.009 \\
<0.001\end{array}$ \\
\hline Carbohydrates $(\mathrm{E} \%)^{\mathrm{c}}$ & -5.2 & $(-6.2,-4.2)$ & $<0.001$ & $\begin{array}{l}9-10 \text { years } \\
12-13 \text { years }\end{array}$ & $\begin{array}{l}-3.7 \\
-6.4\end{array}$ & $\begin{array}{l}(-5.3,-2.0) \\
(-7.7,-5.1)\end{array}$ & $\begin{array}{l}<0.001 \\
<0.001\end{array}$ \\
\hline Added sugars $(E \%)^{f}$ & -9.0 & $(-10.1,-8.0)$ & $<0.001$ & & -9.3 & $(-10.3,-8.2)$ & $<0.001$ \\
\hline Fibre $(\mathrm{g})$ & 3.3 & $(2.2,4.4)$ & $<0.001$ & & 3.4 & $(2.3,4.6)$ & $<0.001$ \\
\hline Retinol equivalent $(\mu \mathrm{g})^{\mathrm{g}}$ & 1.31 & $(1.18,1.46)$ & $<0.001$ & & 1.32 & $(1.19,1.47)$ & $<0.001$ \\
\hline$\alpha$-Tocopherol $(\mu \mathrm{g})^{\mathrm{g}}$ & 1.07 & $(0.98,1.17)$ & 0.13 & & 1.06 & $(0.97,1.17)$ & 0.20 \\
\hline Vitamin D $(\mu \mathrm{g})^{\mathrm{g}}$ & 1.46 & $(1.25,1.71)$ & $<0.001$ & & 1.45 & $(1.24,1.70)$ & $<0.001$ \\
\hline Thiamin $(\mathrm{mg})^{\mathrm{h}}$ & 0.17 & $(0.06,0.28)$ & 0.002 & $\begin{array}{l}\mathrm{BMI}=15.1 \\
\mathrm{BMI}=21.8\end{array}$ & $\begin{array}{l}-0.02 \\
0.29\end{array}$ & $\begin{array}{l}(-0.22,0.18) \\
(0.13,0.45)\end{array}$ & $\begin{array}{l}0.39 \\
<0.001\end{array}$ \\
\hline Riboflavin (mg) & 0.14 & $(0.00,0.28)$ & 0.05 & & 0.13 & $(-0.02,0.28)$ & 0.09 \\
\hline Vitamin C (mg) & -11 & $(-22,-0.54)$ & 0.04 & & -13 & $(-24,-1)$ & 0.03 \\
\hline Calcium (mg) & 74 & $(13,134)$ & 0.02 & & 59 & $(-2,120)$ & 0.06 \\
\hline Iron $(\mathrm{mg})^{\mathrm{g}, \mathrm{i}}$ & 1.08 & $(1.01,1.15)$ & 0.03 & & 0.79 & $(0.43,1.13)$ & 0.14 \\
\hline
\end{tabular}

Reference group is control subjects.

${ }^{a}$ Multiple linear regression analysis adjusted for sex, age and BMI

${ }^{\mathrm{b}} \mathrm{CI}$, confidence interval

${ }^{\mathrm{c}}$ An interaction term between group (diabetic or control) and age was included in the multiple model

${ }^{\mathrm{d}}$ An interaction term between group (diabetic or control) and sex was included in the multiple model

${ }^{\mathrm{e}}$ An interaction term between BMI and age was included in the multiple model.

${ }^{\mathrm{f}}$ Interaction terms between BMI and sex was included in the multiple model.

${ }^{\mathrm{g}}$ The variables have been log transformed and the results presented are back-transformed (see statistical methods)

${ }^{\mathrm{h}}$ Interaction terms between group (diabetic or control) and BMI and between BMI and thiamine were included in the multiple regression model.

The 10th and 90th percentiles of BMI in all participants are used to present the results.

${ }^{\mathrm{i}}$ An interaction term between group (diabetic or control) and BMI was included in the multiple model.

differences were found among the 9-10-year-olds (data not shown).

\section{Discussion}

The present study shows that dietary intake among diabetic children and adolescents has negative characteristics in relation to atherosclerosis, and specifically with regard to intake of fibre, percentage of energy from fat and saturated fat, and intake of fruits and vegetables.

Few studies have reported in detail the dietary intake of children and adolescents with type 1 diabetes [10-17]. This study reports on all aspects of dietary intake, including intake of macro- and micronutrients, as well as intake of selected food items. To our knowledge no other populationbased study of detailed dietary intake among young diabetic subjects has been published. Furthermore, the present study has a larger number of participants and reports on a more limited age span than previously published studies in Europe. An American study was recently published with more participants than the present study; however without a control group and using a less specific method based on memory of preceding weeks' intake [10]. The control group in this study, a national representative group of 9-13-yearolds, is unique in the sense that its members conducted the same dietary recording as the diabetic group and had a high response rate $(81-84 \%)$.

For comparison of the intake of nutrients with current recommendations, the European recommendations [19] and the NNR were used [18]. Both the diabetic and the healthy population in Norway are recommended to follow the NNR [18]. However, diabetic patients are also recommended to have a regular eating pattern, so that insulin injections will be easier to administer [26], and also to help minimise the risk of hypoglycaemia and fluctuations in blood glucose. 
Table 4 Intake of selected food items among diabetic and control subjects

\begin{tabular}{|c|c|c|c|c|c|c|}
\hline & \multicolumn{3}{|l|}{ 9-10-year-olds } & \multicolumn{3}{|l|}{ 12-13-year-olds } \\
\hline & $\begin{array}{l}\text { Diabetic subjects } \\
(n=71)\end{array}$ & $\begin{array}{l}\text { Control subjects } \\
(n=808)\end{array}$ & $p$-value ${ }^{\mathrm{a}}$ & $\begin{array}{l}\text { Diabetic subjects } \\
(n=106)\end{array}$ & $\begin{array}{l}\text { Control subjects } \\
(n=1,001)\end{array}$ & $p$-value ${ }^{\mathrm{a}}$ \\
\hline Fruit and vegetables ${ }^{\mathrm{b}}, \mathrm{g}$ & $211(189-257)$ & $220(209-233)$ & 0.79 & $213(187-253)$ & $205(193-220)$ & 0.67 \\
\hline Fruit, $g$ & $67(55-104)$ & $56(54-63)$ & 0.09 & $67(26-55)$ & $28(26-31)$ & 0.17 \\
\hline Vegetables, g & $67(45-82)$ & $51(47-57)$ & 0.08 & $60(49-73)$ & $50(47-55)$ & 0.03 \\
\hline Fruit juices, $g$ & $0(0-29)$ & $9(0-38)$ & 0.03 & $0(0-0)$ & $0(0-38)$ & 0.04 \\
\hline Potatoes, $\mathrm{g}$ & $35(18-44)$ & $35(35-35)$ & 0.46 & $44(35-53)$ & $35(32-35)$ & 0.02 \\
\hline Full fat milk, $g$ & $0(0-8)$ & $13(8-20)$ & 0.001 & $8(0-18)$ & $8(0-9)$ & 0.35 \\
\hline Low fat milk, $g$ & $185(115-288)$ & $208(179-225)$ & 0.98 & $174(113-204)$ & $113(95-130)$ & 0.03 \\
\hline Skimmed milk, g & $0(0-21)$ & $0(0-0)$ & 0.12 & $0(0-0)$ & $0(0-0)$ & 0.97 \\
\hline Wholemeal bread, g & $29(0-75)$ & $19(13-22)$ & 0.23 & $10(0-29)$ & $13(10-19)$ & 0.62 \\
\hline White bread, $\mathrm{g}$ & $10(0-18)$ & $20(18-23)$ & 0.001 & $14(9-23)$ & $30(26-35)$ & 0.01 \\
\hline Fish (total), $\mathrm{g}$ & $31(25-40)$ & $19(15-23)$ & 0.001 & $21(12-29)$ & $6(1-12)$ & 0.09 \\
\hline Meat (total), g & $108(96-118)$ & $85(80-89)$ & 0.001 & $125(104-138)$ & $88(83-94)$ & $<0.001$ \\
\hline Soft drinks with sugar, $g$ & $0(0-19)$ & 265 (245-289) & $<0.001$ & $0(0-0)$ & $365(345-390)$ & $<0.001$ \\
\hline Diet soft drinks, $g$ & $133(75-183)$ & $0(0-0)$ & $<0.001$ & $206(125-250)$ & $0(0-0)$ & $<0.001$ \\
\hline Sugar and sweets, $g$ & $20(14-28)$ & $32(30-35)$ & $<0.001$ & $22(15-30)$ & $38(36-42)$ & $<0.001$ \\
\hline
\end{tabular}

Values are median $(95 \% \mathrm{CI})$

${ }^{a}$ Mann-Whitney $U$-test

${ }^{\mathrm{b}}$ Includes fruit, vegetables, fruit juices and potatoes

The nutritional counselling of newly diagnosed diabetic children in Norway is not consistent, and not all are guided by a trained dietician. The NNR are comparable to the European recommendations (DNSG) [19], except for MUFA (NNR: 10-15 E\% vs DNSG: 10-20 E\%), carbohydrates (NNR: $50-60$ E\% vs DNSG: 45-60 E\%) and fibre (NNR: 25-35 g/day vs DNSG: $>40$ g/day).

Diabetic subjects in our study had a higher intake of fat and saturated fat than the current recommendation, as has been reported by others $[10-12,14,17,27]$. They also had a higher intake than healthy control subjects, which previously has only been reported among female patients [28]. Meat intake provided $22 \%$ and dairy products (milk, cheese, butter) $48 \%$ of total intake of saturated fat (data not shown). The high fat intake may be related to carbohydrate avoidance following concerns about adjusting insulin around carbohydrate intake, rather than to diabetic children actively seeking a high-fat diet. However, saturated fat is the principal dietary determinant of LDL-cholesterol [29], and young diabetic subjects should be guided to decrease their intake of saturated fat and possibly increase their intake of MUFA. A Finnish study [30] among young diabetic adolescents showed that intake of saturated fat explained $15 \%$ of the variation in LDL-cholesterol.

In the present study, the diabetic subjects had an intake of MUFA in accordance with recommendations and higher intake than control subjects, as shown by others [16, 27]. Donaghue et al. [31] demonstrated among 23 type 1 diabetic patients that a modest increase (11 $\mathrm{E} \%$ to $16.3 \mathrm{E} \%$ ) in the
MUFA content of the diet has the potential to improve glycaemic control and lipid profile.

Intake of energy from added sugars among diabetic children and adolescents was within the recommended level, and much lower than among healthy control subjects. This is mostly explained by the low intake of soft drinks with sugar compared with healthy control subjects (Table 4). Among healthy subjects a high intake of added sugar and soft drinks has been associated with overweight [32]. In the present study, however, diabetic subjects had a higher BMI than control subjects, in spite of lower intake of soft drinks. Several studies have reported that a higher proportion of adolescents with type 1 diabetes are overweight compared with their control subjects [16, 33, 34]. Multiple injection therapy has been found by several studies to be a main predictor of weight gain $[35,36]$, a finding explained in some studies by decreased urinary caloric loss after improving glycaemic control [37], while others explain it by increased caloric intake due to the flexibility allowed by intensified treatment [35]. In our study there was no significant difference in energy intake between diabetic and control subjects. However, physical activity is not included in our analysis and could explain the difference in BMI.

Fibre intake was lower than the recommendations among all diabetic subjects, but higher than the intake among control subjects. This is in accordance with some studies $[10,11,16,17,27,38]$, while others have found that young diabetic subjects have fibre intakes within the recommen- 
ded levels $[11,13,14]$. The main sources of fibre intake were bread and cereals (data not shown). EURODIAB, a study of 2062 diabetic adults, demonstrated that high fibre intakes were independently related to beneficial alterations of the serum cholesterol pattern in men and to a lower risk of cardiovascular disease in European type 1 diabetic women [4].

Intake of micronutrients was satisfactory compared with recommendations, except for intake of vitamin D. An insufficient vitamin $\mathrm{D}$ intake has also been reported by others $[12,16,27]$. A low intake of fish and the fact that only $36 \%$ of diabetic subjects used cod liver oil could explain the low intake of vitamin D. Intake of fish is associated with a reduction in coronary heart disease mortality risk [39]. Intake of vitamin $\mathrm{C}$ was lower among diabetic subjects than control subjects, and can be explained by the difference in intake of vitamin $\mathrm{C}$ from orange juice (diabetic group: $8 \%$, control group: $14 \%$, $p<0.000$ ) and squash (diabetic group: $3 \%$, control group: $14 \%, p<0.000)$.

It is well known that high intakes of fruits and vegetables have a positive health effect, especially in relation to cardiovascular disease [40, 41]. In the present study, intake of fruits and vegetables among diabetic subjects was low ( $210 \mathrm{~g}$ /day) compared with the recommendation of five portions of fruits and vegetables per day $(500 \mathrm{~g} /$ day for children [42]). Only three studies [15-17] (one only for girls) have reported intakes of fruits and vegetables among young diabetic subjects. They found intakes of 300-700 $\mathrm{g} / \mathrm{day}$, which is much higher than the amounts found in the present study.

$\mathrm{HbA}_{1 \mathrm{c}}$ was lower among 9-to 10-year-olds than among 12-to 13-year-olds. With increasing age, diabetic children are given more responsibility in the management of their disease. Furthermore, glycaemic control frequently deteriorates during the adolescent growth spurt, due both to rising insulin requirements and to poor compliance with the frequent blood testing and insulin injections required for proper management [43]. A study by Larsen et al. [44] showed a high prevalence of silent coronary atheromatosis in type 1 diabetic patients in spite of fair metabolic control. The diabetic children and adolescents in the present study had fair metabolic control; at the same time their diet could have been better. This implies that both good metabolic control and a healthy diet are important goals in the counselling of young diabetic subjects. With regard to counselling, the differences seen in intake of fat, fruits and vegetables according to parental levels of education suggest that more guidance of adolescents with less well educated parents would be helpful.

There are several limitations of our study. First, the differences between the two surveys included in the present paper, for although the same method was used, the surveys were carried out 4 years apart, and in different seasons. General changes in the dietary intake during this period are possible. However, the main new public health issue after the results of UNGKOST-2000 was to reduce the intake of sugar-sweetened soft drinks [21]. Among the diabetic subjects, intake of such soft drinks was low, but this was probably not due to focus on reduced intake, since low intake of sugar-sweetened soft drinks in Norway has been reported earlier among young diabetic subjects [17]. The diabetic subjects recorded their diet during the winterspring season and the control subjects during the autumnwinter season. In Norway intake of citrus fruits and dietary cholesterol has been shown to vary according to the season among adults [45]. November and March had the highest intake of citrus fruits, while cholesterol was highest in June [45]. This variation would not change the outcome of our results. There were no geographical differences in proportions of participants from the five main different regions of Norway $(p=0.089)$ between the two studies. Moreover, no differences were observed between diabetic and control subjects according to the duration of parents' education. The difference in response rate between the diabetic and control subjects ( $41 \%$ vs $81-84 \%)$ indicates that there may be differences in motivation and health-consciousness between diabetic and control subjects, as well as between the diabetic participants and those who did not participate in the dietary study (non-participants $n=270$ ). For 200 of the diabetic non-participants, $\mathrm{HbA}_{1 \mathrm{c}}$, weight and height were available from the NCDQ. $\mathrm{HbA}_{1 \mathrm{c}}$ and $\mathrm{BMI}$ were significantly lower $(p<0.05$ and $p<0.01$, respectively) among the dietary participants than among non-participants in analysis adjusted for age and $\operatorname{sex}\left(\mathrm{HbA}_{1 \mathrm{c}}\right.$ mean difference $=0.2 \%$; BMI mean difference $=0.9 \mathrm{~kg} / \mathrm{m}^{2}$ ). This may also be the case for dietary intake, namely that diabetic non-participants possibly had a less healthy diet than the participants, and that the differences in intake of fat and saturated fat between diabetic and control subjects might have been even more pronounced if the participation rate had been higher. The response rate is low compared with other studies (41\% vs $44-94 \%)$ [11, 13, 15-17]. A reason for the low response rate may be the considerable effort of detailed registration of food intake for 4 days. This method, however, is the 'gold standard,' giving detailed information on food and nutrient intake.

Another limitation is the fact that dietary data were selfreported, which often results in under-reporting of energy intake [46]. According to Goldberg et al. [47], a ratio between energy intake and basal metabolic rate of less than 1.06 may indicate under-reporting. In the present study, there were no differences in the proportions of underreporters between diabetic and control subjects in either age group or of either sex. The prevalence of under-reporting is comparable to that reported by others [48]. However, there 
were more under-reporters among adolescents (aged 1213 years) than among children (aged 9-10 years). This could be due to self-reporting by adolescents, whereas in children data were recorded by the parents.

In conclusion, this study shows that intake of energy from fat and saturated fat among diabetic subjects exceeded current Norwegian recommendations, while intake of fibre, fruit and vegetables was too low. Saturated fat and fibre intake are the most critical dietary factors in regard to development of atherosclerosis among diabetic subjects, and knowing that this development starts in early years, it is important to attain a favourable nutritional intake in young people to avoid long-term complications. This is probably also important even if the goal of fair metabolic control is reached. This study supports the idea that nutritional guidance, especially in relation to fat quality and quantity, as well as intake of fibre, fruit and vegetables, should be emphasised even more in the treatment of children and adolescents with type 1 diabetes.

Acknowledgements The authors thank all participants in the Norwegian Childhood Diabetes and Quality project. This project was financed with the aid of EXTRA funds from the Norwegian Foundation for Health and Rehabilitation.

Duality of interest The authors are not aware of any duality of interest.

\section{References}

1. Dahl-Jørgensen K, Larsen JR, Hanssen KF (2005) Atherosclerosis in childhood and adolescent type 1 diabetes: early disease, early treatment? Diabetologia 48:1445-1453

2. Laing SP, Swerdlow AJ, Slater SD et al (2003) Mortality from heart disease in a cohort of 23,000 patients with insulin-treated diabetes. Diabetologia 46:760-765

3. Toeller M, Buyken AE, Heitkamp G et al (1999) Associations of fat and cholesterol intake with serum lipid levels and cardiovascular disease: the EURODIAB IDDM Complications Study. Exp Clin Endocrinol Diabetes 107:512-521

4. Toeller M, Buyken AE, Heitkamp G, de Pergola G, Giorgino F, Fuller JH (1999) Fiber intake, serum cholesterol levels, and cardiovascular disease in European individuals with type 1 diabetes. EURODIAB IDDM Complications Study Group. Diabetes Care 22(Suppl 2):B21-B28

5. Li S, Chen W, Srinivasan SR et al (2003) Childhood cardiovascular risk factors and carotid vascular changes in adulthood: the Bogalusa Heart Study. JAMA 290:2271-2276

6. Strong JP, Malcom GT, McMahan CA et al (1999) Prevalence and extent of atherosclerosis in adolescents and young adults: implications for prevention from the pathobiological determinants of atherosclerosis in youth study. JAMA 281:727-735

7. Viikari JS, Raitakari OT, Simell O (2002) Nutritional influences on lipids and future atherosclerosis beginning prenatally and during childhood. Curr Opin Lipidol 13:11-18

8. Järvisalo MJ, Raitakari M, Toikka JO et al (2004) Endothelial dysfunction and increased arterial intima-media thickness in children with type 1 diabetes. Circulation 109:1750-1755
9. Järvisalo MJ, Jartti L, Näntö-Salonen K et al (2001) Increased aortic intima-media thickness: a marker of preclinical atherosclerosis in high-risk children. Circulation 104:2943-2947

10. Mayer-Davis EJ, Nichols M, Liese AD et al (2006) Dietary intake among youth with diabetes: the search for diabetes in youth study. J Am Diet Assoc 106:689-697

11. Hackett AF, Court S, McCowen C, Parkin JM (1986) Dietary survey of diabetics. Arch Dis Child 61:67-71

12. Randecker GA, Smiciklas-Wright H, McKenzie JM et al (1996) The dietary intake of children with IDDM. Diabetes Care 19:1370-1374

13. Samuelson G, Lenner RA, Carlgren G et al (1989) Food and nutrient intakes in Swedish diabetic children. Eur J Clin Nutr 43:801-803

14. Schober E, Langergraber B, Rupprecht G, Rami B (1999) Dietary intake of Austrian diabetic children 10 to 14 years of age. J Pediatr Gastroenterol Nutr 29:144-147

15. Virtanen SM, Räsänen L, Mäenpää J, Åkerblom HK (1987) Dietary survey of Finnish adolescent diabetics and non-diabetic controls. Acta Pædiatr Scand 76:801-808

16. Pietiläinen KH, Virtanen SM, Rissanen A, Rita H, Mäenpää J (1995) Diet, obesity and metabolic control in girls with insulin dependent diabetes mellitus. Arch Dis Child 73:398-402

17. Lorentsen N, Bergstad I (2005) Diet, self-management and metabolic control in Norwegian teenagers with type 1 diabetes. Scand J Nutr 49:27-37

18. Nordic Council of Ministers (2005) Nordic nutrition recommendations 2004. Integrating nutrition and physical activity. 4th edn. Norden, Copenhagen, Denmark

19. Mann JI, De Leeuw I, Hermansen K et al (2004) Evidence-based nutritional approaches to the treatment and prevention of diabetes mellitus. Nutr Metab Cardiovasc Dis 14:373-394

20. Margeirsdottir HD, Larsen JR, Brunborg C, Dahl-Jørgensen K and the Norwegian Study Group for Childhood Diabetes (2006) Nation-wide improvement in HbAlc and complication screening in a benchmarking project in childhood diabetes. A prospective national quality study. Pediatric Diabetes 7(Suppl 5):OP-4 (Abstract)

21. Øverby N, Lillegaard ITL, Johansson L, Andersen LF (2004) High intake of added sugars among Norwegian children and adolescents. Public Health Nutr 7:285-293

22. Andersen LF, Lillegaard ITL, Øverby N, Lytle L, Klepp K-I, Johansson L (2005) Overweight and obesity among Norwegian schoolchildren: changes from 1993 to 2000 . Scand J Public Health 33:99-106

23. Lillegaard ITL, Andersen LF (2005) Validation of a pre-coded food diary with energy expenditure, comparison of underreporters v. acceptable reporters. Br J Nutr 94:998-1003

24. Lillegaard ITL, Øverby NC, Andersen LF (2005) Can children and adolescents use photographs of food to estimate portion sizes? Eur J Clin Nutr 59:611-617

25. Rimestad AH, Løken EB, Nordbotten A (2000) The Norwegian food composition table and the database for nutrient calculations at the Institute for Nutrition Research. Nor J Epidemiol 10:7-10 (in Norwegian)

26. National Nutrition Council (1995) Dietary guidelines for health institutions. Universitetsforlaget, Oslo, Norway (in Norwegian)

27. Dorchy H, Bourguet K (1997) Nutritional intake of Belgian diabetic children. Diabetes Care 20:1046-1047 (Letter)

28. Faulkner MS, Chao WH, Kamath SK et al (2006) Total homocysteine, diet, and lipid profiles in type 1 and type 2 diabetic and nondiabetic adolescents. J Cardiovasc Nurs 21:47-55

29. Franz MJ, Bantle JP, Beebe CA et al (2002) Evidence-based nutrition principles and recommendations for the treatment and prevention of diabetes and related complications. Diabetes Care $25: 148-198$ 
30. Virtanen SM, Räsänen L, Virtanen M et al (1993) Associations of serum lipids with metabolic control and diet in young subjects with insulin-dependent diabetes mellitus in Finland. Eur J Clin Nutr 47:141-149

31. Donaghue KC, Pena MM, Chan AKF et al (2000) Beneficial effects of increasing monounsaturated fat intake in adolescents with type 1 diabetes. Diabetes Res Clin Pract 48:193-199

32. Malik VS, Schulze MB, Hu FB (2006) Intake of sugar-sweetened beverages and weight gain: a systematic review. Am J Clin Nutr $84: 274-288$

33. Ingberg C-M, Särnblad S, Palmér M, Schvarcz E, Berne C, Åman J (2003) Body composition in adolescent girls with type 1 diabetes. Diabet Med 20:1005-1011

34. Danne T, Kordonouri O, Enders I, Weber B (1997) Factors influencing height and weight development in children with diabetes. Results of the Berlin Retinopathy Study. Diabetes Care 20:281-285

35. Holl RW, Grabert M, Sorgo W, Heinze E, Debatin KM (1998) Contribution of age, gender and insulin administration to weight gain in subjects with IDDM. Diabetologia 41:542-547

36. The Diabetes Control and Complications Trial Research Group (2001) Influence of intensive diabetes treatment on body weight and composition of adults with type 1 diabetes in the diabetes control and complication trial. Diabetes Care 24:1711-1721

37. Jacob AN, Salinas K, Adams-Huet B, Raskin P (2006) Potential causes of weight gain in type 1 diabetes mellitus. Diabetes Obes Metab 8:404-411

38. Virtanen SM, Varo P (1988) Dietary fibre and fibre fractions in the diet of Finnish diabetic and non-diabetic adolescents. Eur J Clin Nutr 42:169-175

39. Kønig A, Bouzan C, Cohen JT et al (2005) A quantitative analysis of fish consumption and coronary heart mortality. Am J Prev Med 29:335-346
40. Law MR, Morris JK (1998) By how much does fruit and vegetable consumption reduce the risk of ischaemic heart disease? Eur J Clin Nutr 52:549-556

41. Hung HC, Joshipura KJ, Jiang R et al (2004) Fruit and vegetable intake and risk of major chronic disease. J Natl Cancer Inst 96:1577-1584

42. Andersen LF, Øverby NC, Lillegaard ITL (2004) Intake of fruit and vegetables among Norwegian children and adolescents. Tidsskr Nor Laegeforen 10:1396-1398 (in Norwegian)

43. Gordon CM, Mansfield MJ (1996) Changing need of the patient with diabetes mellitus during the teenage years. Curr Opin Pediatr 8:319-327

44. Larsen J, Brekke M, Sandvik L, Arnesen H, Hanssen KF, DahlJørgensen K (2002) Silent coronary atheromatosis in type 1 diabetic patients and its relation to long-term glycemic control Diabetes 51:2637-2641

45. Johansson L, Solvoll K, Opdahl S, Bjørneboe GE, Drevon CA (1997) Response rate with different distribution methods and reward, and reproducibility of a quantitative food frequency questionnaire. Eur J Clin Nutr 51:346-353

46. Black AE, Goldberg GR, Jebb SA, Livingstone MB, Cole TJ, Prentice AM (1991) Critical evaluation of energy intake data using fundamental principles of energy physiology: 2. Evaluating the results of published surveys. Eur J Clin Nutr 45:583599

47. Goldberg GR, Black AE, Jebb SA et al (1991) Critical evaluation of energy intake data using fundamental principles of energy physiology: 1. Derivation of cut-off limits to identify underrecording. Eur J Clin Nutr 45:569-581

48. Sichert-Hellert W, Kersting M, Schöch G (1998) Underreporting of energy intake in 1 to 18 year old German children and adolescents. Z Ernährungswiss 37:242-251 